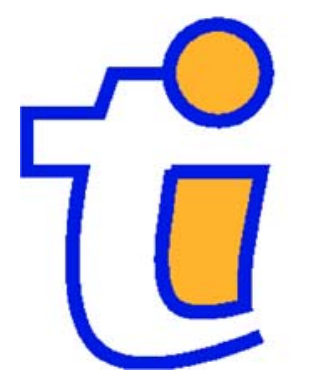

TI 2010-012/3

Tinbergen Institute Discussion Paper

Industry Dynamics and

Entrepreneurship:

An Equilibrium Model

Dennis Fok ${ }^{A}$

André van Ste/B,C

Andrew Burke ${ }^{D}$

Roy ThurikA,B

${ }^{A}$ Erasmus University Rotterdam, and Tinbergen Institute, the Netherlands;

${ }^{B}$ EIM Business and Policy Research, Zoetermeer, the Netherlands;

C University of Amsterdam, and Tinbergen Institute, the Netherlands;

D Cranfield University, UK. 


\section{Tinbergen Institute}

The Tinbergen Institute is the institute for economic research of the Erasmus Universiteit Rotterdam, Universiteit van Amsterdam, and Vrije Universiteit Amsterdam.

Tinbergen Institute Amsterdam

Roetersstraat 31

1018 WB Amsterdam

The Netherlands

Tel.: +31(0)205513500

Fax: $+31(0) 205513555$

Tinbergen Institute Rotterdam

Burg. Oudlaan 50

3062 PA Rotterdam

The Netherlands

Tel.: + $31(0) 104088900$

Fax: $+31(0) 104089031$

Most TI discussion papers can be downloaded at http://www.tinbergen.nl. 


\title{
Industry Dynamics and Entrepreneurship: An Equilibrium Model
}

\author{
Dennis Fok ${ }^{\text {A }}$, André van Stel ${ }^{\text {B, C }}$, Andrew Burke ${ }^{\mathrm{D}}$ and Roy Thurik ${ }^{\text {A, B }}$ \\ ${ }^{\text {A }}$ Erasmus University Rotterdam, the Netherlands \\ ${ }^{B}$ EIM Business and Policy Research, Zoetermeer, the Netherlands \\ ${ }^{\mathrm{C}}$ University of Amsterdam, the Netherlands \\ ${ }^{\mathrm{D}}$ Cranfield University, UK
}

\begin{abstract}
This paper conducts the first general equilibrium analysis of the role of entry, exit and profits in industry dynamics. The benefit of our model is twofold. First, to discriminate between entrants' role of performing the entrepreneurial function of creating disequilibrium and the conventional equilibrating role of moving the industry to a new equilibrium. Second, to discriminate between three aspects of industry dynamics: the effect of entry and exit on market equilibrium, duration of disequilibrium and patterns of adjustment. Using a rich data set of the retail industry, we construct a dynamic simultaneous equilibrium model of profits, entry and exit. We find that indeed entrants play an entrepreneurial function causing long periods of disequilibrium after which a new equilibrium is attained. Moreover, we find ample support for the statement that disequilibrium is the essence of economic progress.
\end{abstract}

Keywords: entry, exit, profits, equilibrium, industrial dynamics, retailing

JEL codes: B50, J01, L00, L1, L26

Contact: André van Stel, ast@eim.nl

First version: February 2009 (The dynamics of entry and exit, EIM Research Report H200907)

This version: January 2010

FileName: Entry_and_Exit_of_Firms_v15.doc

SaveDate: $1 / 12 / 20108: 54$

Acknowledgement: Comments by Philipp Koellinger and Christian Roessler are gratefully acknowledged. The paper has been written in the framework of the research program SCALES carried out by EIM and financed by the Dutch Ministry of Economic Affairs. It benefitted from many visits of André van Stel to Cranfield University and a short stay of Roy Thurik to EM-Lyon. 


\section{Introduction}

While Schumpeter's driver of economic progress is about how entrepreneurs generate shocks which disrupt existing market equilibrium, that of Schultz is about how entrepreneurs adjust to these shocks. Schumpeter (1947) simply assumes that equilibrium is quickly restored after disruption. For Schultz (1975) disequilibria are inevitable features of economic progress. ${ }^{1}$ It takes time to regain equilibrium and the adjustment patterns may vary according to the opportunities and restrictions of entrepreneurial behavior.

In the classical framework entry and exit of firms rather than the entrepreneurial behavior of people play the role of adjustment mechanisms which restore market equilibrium. Net-entry rises when incumbents' profits are supernormal and falls when they are at unsustainable low levels. The only economic function of entry and exit is to be reactive and respond to disequilibrium profit levels. In equilibrium when profits are at normal levels, entry and exit have no role and are assumed to be in a steady state where entry equals exit. These predictions are at odds with real life observations. As is shown in Table 1 of the next section, entry and exit rates are not equal to zero, and their long-run averages are often also not equal to each other. Implicit in the analysis is that adjustment is frictionless and hence forsaking the importance of the duration of the disequilibrium stage and the patterns of adjustment in disequilibrium. It is an adjustment process driven by firms having full and perfect information rather than by people having imperfect information and who are in need of learning. The present paper is about all three phenomena which Schumpeter and Schultz identify as the essence of economic progress: the effect of entry and exit on market equilibrium, duration of disequilibrium and patterns of adjustment.

Baumol (2002) points out that one of the most disappointing shortcomings in the classical approach is that it does not explain the enduring success of capitalism in generating economic growth. This might have to do with the invisibility of the role of the entrepreneur (Barreto, 1989). As Schumpeter (1947) argues, classical analysis is preoccupied with competition without innovation and by consequence is focused on the sub plot of adjustment around any given equilibrium. It does not enlighten our understanding of the main mystery which surrounds the determinants of the long-term dynamic equilibrium itself. Moving the focus of attention to this question involves the role of innovation and differentiation. It moves the attention from the price competition with fixed technology which is central in the classical framework towards competition involving new goods and services or new technology and organization. In doing so it also introduces the potential for an entrepreneurial function for entrants, i.e., to discover, experiment, refine and exploit this potential. No longer are entrants imitative 'me too' aspiring firms that seize their moment only when incumbents' profits have become excessive. Instead, entrants bring innovation and differentiation to the market and in the process introduce new profit opportunities. In this framework they reverse the classical causation so that equilibrium normal profit levels are determined by entry and exit rather than the other way around. In terms of entrepreneurial roles: it is the combination of the Schumpeterian entrepreneur creating instability and destruction and the more conventional Austrian entrepreneur combining resources to recreate stability (Wennekers and Thurik, 1999). The Schumpeterian entrepreneur

\footnotetext{
${ }^{1}$ See also http://nobelprize.org/nobel_prizes/economics/laureates/1979/schultz-lecture.html: "The transformation of agriculture into an increasingly more productive state, a process that is commonly referred to as "modernization", entails all manner of adjustments in farming as better opportunities become available. I have shown that the value of the ability to deal with disequilibria is high in a dynamic economy (Schultz, 1975). Such disequilibria are inevitable. They cannot be eliminated by law, by public policy, and surely not by rhetoric. Governments cannot perform efficiently the function of farm entrepreneurs."
} 
creates potential and the Austrian entrepreneur realizes it (Nooteboom, 2000). This realization hinges around the process of market dynamics with the interplay of not just entry and exit but also profit as the indicator of competition (Kirzner, 1973). Implementing this view in the world of economic modeling immediately raises the question how the interplay of entry, exit and profits works; particularly distinguishing between short term relationships where the classical assumption of fixed technology may be more realistic and longer term effects where entrants may introduce new disruptive technologies to the market.

The present paper specifies a full equilibrium model explaining entry, exit and profit while also capturing the duration of disequilibrium and patterns of adjustment. We account for both short and long run effects making use of a rich data set on Dutch retailing. We construct a dynamic simultaneous equilibrium model of entry, exit and profits allowing for both short- and long-run effects in order to capture the Schumpeterian disequilibrium effects as well as the conventional Austrian equilibrium effects of entrepreneurial entry, exit and profit. In this fashion we can also discriminate between three dimensions of the adjustment process towards a new equilibrium: net change of the entry, exit and profit levels as well as Schultz's time and pattern of these changes. To our knowledge this is the first empirical analysis of the simultaneous interrelationship between entry, exit and industry profits. The model we propose will be investigated using four types of one-time shocks: to profits, the number of entrants, the number of exits and consumer spending. Telling the story of the adjustment process to a new equilibrium using shocks and discriminating between three dimensions is the main contribution of the present paper. Previous analyses have only investigated these effects on a partial equilibrium basis. Therefore, this analysis sheds light on the validity and strength of (once presumed, competing) economic models of entry and exit that have dominated debate in industrial economics for most of the last century.

The next section of the paper provides a description of the data. This is followed by the specification of the model in section three. The results are discussed in the succeeding section with a focus on the analysis of impulse response functions. Section five concludes.

\section{Data}

We investigate the interrelation between entry and exit levels, the number of firms and profit levels. These four variables are the key variables in an error-correction model which we will develop in the next section. The model is estimated using data for a panel of shop types in the Dutch retail sector. ${ }^{2}$ The current section describes the measurement and data sources for the key variables of our model as well as for the other covariates. This section also provides some descriptive statistics and a series of tests on stationarity and cointegration for the key variables in our analysis. The results of these tests are used to develop our error-correction model in the next section. But first entry and exit rates of ten developed countries for a recent period are discussed. ${ }^{3}$

From Table 1 it is clear that in practice, entry and exit rates are not equal to zero, and they are often also not equal to each other. Instead, firm entry and exit are observed to be a persistent feature of these economies. Taken together these observations indicate that disequilibria are likely to be vital characteristics of modern economies. Hence, the assumptions on the role of

\footnotetext{
${ }^{2}$ The industries in our data base are defined at (approximately) fourth digit level. Hence, these industries are quite narrowly defined. Because firms in the retail sector are almost always shops, we use the terms shop type and industry interchangeably throughout this paper.

${ }^{3}$ In Table 1, an entry is defined as a new firm (either a new-firm start-up or a new subsidiary company), where at least one person is active for at least one hour per week (i.e. it has to be an active new firm). An exit occurs when an active firm leaves the market, either voluntarily or involuntarily. See EIM (2009) for details.
} 
entry and exit made in the classical economic framework may be overly restrictive by ignoring an entrepreneurial function.

Table 1: Entry and exit as a percentage of the number of firms, 1997-2006

\begin{tabular}{lrrrr|rrrr}
\hline & \multicolumn{3}{c}{ Entry } & \multicolumn{4}{c}{ Exit } \\
& 1997 & 2000 & 2003 & 2006 & 1997 & 2000 & 2003 & 2006 \\
\hline Belgium & 7.2 & 6.7 & 6.5 & 8.4 & 6.7 & 6.8 & 6.1 & 6.3 \\
Denmark & 10.4 & 11.7 & 10.8 & 13.3 & 10.0 & 9.5 & 10.5 & 13.3 \\
Finland & 9.7 & 8.6 & 9.4 & 11.5 & 7.8 & 7.4 & 7.6 & 7.9 \\
France & 6.8 & 6.9 & 7.8 & 6.6 & 7.0 & 5.5 & 4.8 & 5.2 \\
Germany & 12.0 & 9.6 & 9.7 & 8.1 & 8.0 & 7.1 & 6.9 & 6.8 \\
Ireland & 13.1 & 15.1 & 12.5 & 14.5 & 7.9 & 5.7 & 3.8 & 7.6 \\
Italy & 6.9 & 7.7 & 7.3 & 7.6 & 6.3 & 5.4 & 5.9 & 6.7 \\
Netherlands & 10.2 & 11.1 & 8.0 & 10.5 & 5.5 & 6.1 & 6.5 & 6.4 \\
United Kingdom & 12.7 & 13.3 & 13.2 & 12.1 & 11.0 & 13.1 & 12.7 & 9.3 \\
United States & 12.2 & 10.1 & 9.2 & 9.9 & 9.5 & 8.9 & 8.7 & 9.1 \\
\hline
\end{tabular}

Source: EIM (2009).

\section{Our data set}

We use a data base for 41 shop types in the retail sector over the period 1980-2000. Our data base combines variables from two major sources: the Dutch Central Registration Office (CRK) and a panel of independent Dutch retailers (establishments) called 'Bedrijfssignaleringssysteem' (BSS) (interfirm comparison system) which was operated by EIM Business and Policy Research in Zoetermeer. The data are complemented using information from several sources. As the number of shop types investigated in BSS has varied in the 1980s and 1990s, our data base is an unbalanced panel. By and large, we have 28 shop types with data for the 1980s and 1990s and 13 shop types with data for the 1990s only. The exact data period per shop type is given in Table 2. The table also contains averages for some key variables in our model. Details on the measurement and source for each variable are given below. We apply several corrections to the raw data in order to make the data ready for analysis.

Raw data on the number of firms $(N)$ and the numbers of entries $(E)$ and exits $(X)$ are obtained from the Dutch Central Registration Office (CRK). CRK provides data on the number of new registrations and deregistrations of establishments for each shop type. Over time the sectoral classification of shop types used by CRK changed several times and we correct for trend breaks because of these changes.

Total industry profits $(\pi)$ are computed by multiplying average profits per firm by the total number of firms in a shop type. Raw data on average (net) profit per firm are taken from BSS. This panel was started by EIM in the 1970s and each year a large number of firms were asked for their financial performance. Although the panel changes from year to year (each year some firms exit the panel while some others enter), it is important to note that we compute the relative change in average profit based on only those firms present in the panel in two consecutive years. Hence, the dynamics of these variables are not influenced by changes in the composition of the 
panel. ${ }^{4}$ Until the beginning of the 1990s average profit levels are computed based on about seventy individual retail stores per shop type but from the beginning of the 1990s the coverage of the panel decreases, i.e., less firms participate so that shop type averages become less reliable. Fortunately, the timing of this decrease coincides with the start of average financial performance registration by Statistics Netherlands (CBS) at low sectoral aggregation levels. Hence, from the early 1990s onwards, we have information on the development over time of these variables from two sources: BSS and CBS. Differences between these two sources are small which supports the reliability of our constructed times series. From 1994 onwards we use the average of the annual relative change implied by these two sources. ${ }^{5}$

Data on total consumer spending on the products and services sold in a certain shop type is taken from Statistics Netherlands (publication 'Budgetonderzoeken' or Budget statistics). ${ }^{6}$ The variables modal income and unemployment are also taken from Statistics Netherlands, while the (nominal) interest rates are taken from Thomson Reuters Datastream, a provider of financial data. $^{7}$. Finally, for total industry profits, modal income, consumer spending, and the nominal interest rate, we use a consumer price index to correct for inflation.

In Table 2 we give an overview of the available data. Table 2 shows that some shop types have grown in terms of the number of shops over the sample period, while other shop types have shrunk. For instance, the average number of entrants for the shop type "grocers/supermarkets" is 743 while over the same period of time the average number of exits equals 932. This implies that the category shrunk with, on average, 189 shops each year. Over the entire sample period of 21 years this category shrunk with about 189 × $21=3969$ stores. Note that at the same time this category witnessed an inflation-corrected yearly profit decrease of about $0.7 \%$ and an increase in consumer spending of about $0.3 \%$. In all shop types there are relatively many stores entering the market and relatively many shops leaving the market (relative to the number of firms). In some shop types entry dominates exit, while in others exit dominates entry. Remarkably, even in shop types where there is no net change in the number of stores, there are still entrants and exits. For example, the category "fish shops" has on average 114 stores entering and 114 stores exiting the market, corresponding to $11 \%$ of the population of firms. Table 2 clearly shows that entry and exit levels are significantly positive over a longer period of time. This suggests that the "classical idea" of a steady-state level with entry and exit rates equal to zero is not a sufficient account of the patterns in the data. It seems that there exists a long-term persistent level of entry and exit in each shop type. As explained earlier, the current paper develops a model where these long-term entry and exit levels are explicitly specified.

\footnotetext{
${ }^{4}$ Hence we choose a base year to compute the level of average profits or turnover, and next we compute the levels for the other years making use of the relative changes of only those firms present in two consecutive years. As most firms stayed in the panel for many years, these relative changes are also based on a substantial number of firms, but this way we correct for trend breaks introduced by a changing composition of the panel (e.g. when a firm with exceptionally high profits would enter or exit the panel). For the base year we always choose a year for which the number of participating firms in the panel is high.

${ }^{5}$ Ideally, one would like to use information from Statistics Netherlands (CBS) as this is the national statistical office in the Netherlands. However, as the number of firms in a shop type (which is approximately fourth digit level) is often small, and the number of firms is rounded to thousands in CBS statistics, using the CBS data also implies some extent of measurement error. Therefore we use information from both sources to estimate the dynamic pattern of the profit and turnover variables.

${ }^{6}$ Total consumer spending was computed by multiplying the variables average household spending, the total number of households in the Netherlands and the share of a certain shop type in total household spending.

${ }^{7}$ See www.datastream.com. In particular we used the series HOLIB1Y.
} 
Table 2: Shop types and key summary statistics

\begin{tabular}{|c|c|c|c|c|c|c|}
\hline & Time span & $\begin{array}{l}\text { Avg. no. } \\
\text { firms }\end{array}$ & $\begin{array}{l}\text { Avg. no. } \\
\text { entries }\end{array}$ & $\begin{array}{l}\text { Avg. no. } \\
\text { exits }\end{array}$ & $\begin{array}{l}\text { Avg. profit } \\
\text { growth }\end{array}$ & $\begin{array}{l}\text { Avg. growth } \\
\text { consumer } \\
\text { spending }{ }^{1}\end{array}$ \\
\hline & & $(\bar{N})$ & $(\bar{E})$ & $(\bar{X})$ & $(\overline{\log \pi})$ & $(\overline{\Delta \log C S})$ \\
\hline grocers/supermarkets & $1980-2000$ & 9044 & 743 & 932 & -0.0074 & 0.0033 \\
\hline butchers & $1980-2000$ & 5885 & 448 & 590 & -0.0443 & -0.0222 \\
\hline greengrocers & $1980-2000$ & 4489 & 458 & 595 & -0.0330 & 0.0014 \\
\hline fish shops & $1980-2000$ & 1019 & 114 & 114 & 0.0046 & 0.0095 \\
\hline bakers & $1980-2000$ & 5353 & 403 & 485 & -0.0153 & -0.0027 \\
\hline confectioners & $1980-2000$ & 2092 & 276 & 306 & -0.0064 & 0.0094 \\
\hline tobacco shops & $1980-2000$ & 3421 & 149 & 270 & -0.0141 & -0.0050 \\
\hline liquor stores & $1980-2000$ & 2627 & 258 & 321 & -0.0030 & -0.0005 \\
\hline textiles men's wear & $1989-2000$ & 4986 & 190 & 399 & -0.0180 & 0.0274 \\
\hline shoe stores & $1980-2000$ & 3598 & 291 & 325 & 0.0126 & 0.0073 \\
\hline households goods shops & $1980-2000$ & 2559 & 273 & 289 & -0.0151 & 0.0041 \\
\hline furniture & $1980-2000$ & 4840 & 421 & 386 & 0.0596 & -0.0165 \\
\hline furnishing + furniture (mixed) & $1980-2000$ & 4090 & 216 & 280 & -0.0449 & 0.0069 \\
\hline paint, glass and wall-paper & $1980-2000$ & 5891 & 251 & 361 & -0.0013 & -0.0016 \\
\hline hardware stores & $1980-2000$ & 6364 & 266 & 333 & 0.0035 & -0.0074 \\
\hline bicycle stores & $1980-2000$ & 4129 & 187 & 239 & 0.0166 & 0.0204 \\
\hline photographer's shops & $1980-2000$ & 1806 & 149 & 150 & 0.0126 & -0.0099 \\
\hline Jewelers & $1980-2000$ & 2585 & 232 & 221 & 0.0302 & 0.0250 \\
\hline drug stores & $1980-2000$ & 2982 & 228 & 216 & 0.0288 & 0.0353 \\
\hline Florists & $1980-2000$ & 5475 & 874 & 883 & 0.0112 & 0.0077 \\
\hline pet shops & $1980-2000$ & 2119 & 227 & 221 & 0.0131 & 0.0106 \\
\hline Poultry & $1992-2000$ & 711 & 55 & 82 & -0.0212 & -0.0128 \\
\hline dairy shops & $1980-2000$ & 4350 & 181 & 336 & -0.0518 & -0.0029 \\
\hline Reform & $1989-2000$ & 1801 & 223 & 152 & 0.1198 & -0.0061 \\
\hline baby's clothing & $1989-2000$ & 1537 & 225 & 218 & 0.0880 & 0.0522 \\
\hline children's clothing & $1989-2000$ & 1697 & 264 & 198 & 0.0535 & 0.0578 \\
\hline textiles underwear & $1989-2000$ & 739 & 160 & 115 & 0.1073 & 0.0772 \\
\hline clothing materials & $1989-2000$ & 1795 & 92 & 176 & -0.0098 & -0.0260 \\
\hline leather goods & $1989-2000$ & 875 & 100 & 104 & -0.0115 & 0.0126 \\
\hline electrics & $1980-2000$ & 3472 & 236 & 305 & -0.0111 & 0.0064 \\
\hline audiovisual devices & $1980-2000$ & 3211 & 538 & 471 & 0.0421 & 0.0021 \\
\hline musical instruments & $1989-2000$ & 772 & 75 & 68 & 0.0480 & 0.0108 \\
\hline sewing-machines & $1980-2000$ & 463 & 34 & 46 & -0.0427 & -0.0192 \\
\hline do-it-yourself shop & $1989-2000$ & 3886 & 486 & 389 & 0.0632 & -0.0011 \\
\hline glass, porcelain and pottery & $1980-2000$ & 3567 & 341 & 322 & 0.0275 & -0.0064 \\
\hline office and school materials & $1980-2000$ & 1327 & 125 & 123 & -0.0369 & 0.0263 \\
\hline opticians & $1980-2000$ & 1607 & 160 & 121 & 0.0818 & 0.0776 \\
\hline videotheques & 1989-1997 & 714 & 295 & 284 & 0.0593 & 0.0131 \\
\hline gardening centers & $1989-2000$ & 532 & 103 & 71 & 0.1294 & 0.0833 \\
\hline Toys & $1980-2000$ & 1072 & 183 & 144 & 0.1043 & 0.0302 \\
\hline sport and camping equipment & $1990-2000$ & 2849 & 382 & 276 & 0.0462 & 0.0577 \\
\hline
\end{tabular}

${ }^{1}$ Corrected for inflation.

\section{Testing for stationarity and cointegration}

Before we specify our model we test the key series for stationarity. To this end we use panel unit root tests. There are basically two sets of panel unit root tests. The first set assumes a 
common AR structure across panel members under the null and a common AR structure under the alternative. Popular examples are the Levin et al. (2002) test and the Breitung (2000) tstatistic. The second set of tests assumes individual AR structures. Popular examples in this class are the Im et al. (2003) W-statistic, and the Fisher-type tests (Maddala and Wu, 1999 and Choi, 2001). The alternative hypothesis in this second class of tests is that some of the panel members are stationary. We use the tests as they are implemented in EViews 6, with all the "automatic" options for lag and bandwidth selection. If the majority of the series show a trend we use the tests with the option of individual deterministic trends. Our final conclusion is based on the combined results of the tests. Note that the tests may contradict each other. Furthermore, our sample size is relatively small so that we should not expect a very large power of the tests nor can we be sure that the size of the tests is correct. We therefore see the results of these tests as a way to provide some further descriptive data.

We summarize the test results in Table 3 . The log entry and log exit series do not appear to have a trend. The test results clearly indicate that the log entry and log exit series do not contain a unit root. For the number of firms we have to correct for possible deterministic trends. The tests clearly show that the log of the number of firms is not stationary. Note that entry and exit together measure the change in number of firms. For the log total profit and the log consumer spending in the shop type it is not so clear whether the series contain a trend. Therefore, we present the results for the tests without correcting for trends as well as those where the trend correction is made. Table 3 clearly shows that the log consumer spending does not contain a unit root. For the log of the total profit the results are less clear. We decide to classify this series as non-stationary.

Table 3: p-values of panel unit root tests $\left(\mathrm{H}_{0}\right.$ : unit root (common or individual))

\begin{tabular}{llcc|ccc}
\hline & $\begin{array}{c}\text { Trend in } \\
\text { test? }\end{array}$ & $\begin{array}{c}\text { Common unit root process } \\
\text { Levin, Lin } \\
\text { and Chu t* }\end{array}$ & $\begin{array}{c}\text { Breitung } \\
\text { t-stat }\end{array}$ & $\begin{array}{c}\text { Individual unit root processes } \\
\text { Shin W-stat }\end{array}$ & $\begin{array}{c}\text { ADF - Fisher } \\
\text { Chi-square }\end{array}$ & $\begin{array}{c}\text { PP - Fisher } \\
\text { Chi-square }\end{array}$ \\
\hline $\log E$ & no & 0.003 & - & 0.005 & 0.002 & 0.000 \\
$\log X$ & yes & 0.000 & - & 0.000 & 0.000 & 0.000 \\
$\log N$ & yes & 0.889 & 1.000 & 1.000 & 0.938 & 1.000 \\
$\log \pi$ & no & 0.027 & - & 0.219 & 0.127 & 0.351 \\
& yes & 0.000 & 0.334 & 0.001 & 0.000 & 0.003 \\
$\log C S$ & no & 0.000 & - & 0.010 & 0.001 & 0.004 \\
& yes & 0.000 & 0.659 & 0.000 & 0.000 & 0.000 \\
\hline
\end{tabular}

We next test for cointegration between the number of firms and profits. In our panel set-up we test for cointegration by testing the hypothesis of a unit root in the residuals of a panel regression of $\log$ profit on $\log$ number of firms. Note that this hypothesis corresponds to no cointegration. More specifically we apply the procedure of Pedroni $(1999,2004)$. This procedure is similar to the Engle and Granger (1987) method for a single time series. Again we use this method as implemented in EViews 6 with all the automatic options. There are a number of different test statistics available. However, note that all of these tests are strictly speaking not valid. The tests all make the assumption that the cross-sections are independent. This is not likely to hold as all shop types are dependent on the development of the Dutch economy. Overall the results are mixed. After correcting for trends the Panel PP-Statistic as well as the Panel ADF-Statistic give a p-value of 0 . This corresponds to the existence of cointegration between the two variables. However, other indicators point in the opposite direction. The exact reason for this apparent contradiction is extremely difficult to find. We attribute the finding to a possibly low power of these particular tests. Here we come to the overall conclusion that the profits and the number of firms are indeed cointegrated. 


\section{Model}

In the below model we will discriminate between the short term disequilibrating and long term equilibrating roles of entry and exit while making room for an analysis of the net change, the duration and the pattern of the move from the initial to the next equilibrium.

Denote by $\pi_{i t}$ the total profit in shop type $i=1, \ldots, N$ during year $t=1, \ldots, T_{i}$. Next, $E_{i t}$ and $X_{i t}$ give the number of firms entering and exiting the market for shop type $i$ in year $t$. Finally, $N_{i t}$ gives the number of firms in market $i$ at the beginning of year t. The number of firms at the beginning of year $t+1$ is therefore given by $N_{i t+1}=N_{i t}+E_{i t}-X_{i t}$. In this section we develop a model describing the log of the total profits as well as the log of the number of entrants and the $\log$ of the number of exits. Note that this model also implicitly describes the number of firms.

We specify a model in which the changes in entry, exit and profit are related to short-term dynamics, changes in exogenous variables and to deviations to the steady-state of the market. We denote the exogenous variables related to market $i$ in year $t$ by $Z_{i t}$. We specify an errorcorrection model for all three endogenous variables, which is consistent with the earlier findings that $\log$ entry and $\log$ exit are stationary and that $\log$ profits and $\log$ number of firms are cointegrated. We specify

$$
\left(\begin{array}{l}
\Delta \log E_{i t} \\
\Delta \log X_{i t} \\
\Delta \log \pi_{i t}
\end{array}\right)=A\left(\begin{array}{l}
\Delta \log E_{i t-1} \\
\Delta \log X_{i t-1} \\
\Delta \log \pi_{i t-1}
\end{array}\right)+B \Delta Z_{i t}+\Pi\left(\begin{array}{l}
\log E_{i t-1}-\log E_{i t-1}^{*} \\
\log X_{i t-1}-\log X_{i t-1}^{*} \\
\log \pi_{i t-1}-\log \pi_{i t-1}^{*}
\end{array}\right)+\left(\begin{array}{l}
\varepsilon_{i t} \\
\eta_{i t} \\
\xi_{i t}
\end{array}\right),
$$

where $\log E_{i t}{ }^{*}, \log X_{i t}{ }^{*}$ and $\log \pi_{\mathrm{it}}{ }^{*}$ denote the steady state levels for $\log$ entry, log exit and $\log$ profit, respectively. The steady state levels depend on exogenous variables describing the market situations. These variables are denoted by $W_{i t}^{E}, W_{i t}^{X}$, and $W_{i t}^{\pi}$. Consistent with the finding of cointegration, the steady state relation for profit also involves the number of firms. We model these steady state levels as

$$
\begin{aligned}
& \log E_{i t}^{*}=\gamma_{1 i}+W_{i t}^{E \prime} \delta_{1} \\
& \log X_{i t}^{*}=\gamma_{2 i}+W_{i t}^{X '} \delta_{2} \\
& \log \pi_{i t}^{*}=\gamma_{3 i}+W_{i t}^{\pi \prime} \delta_{3}+\lambda \log N_{i t}+\kappa_{i} t
\end{aligned} .
$$

For the steady state relation of profit and number of firms we allow for a trend. We therefore allow that the average profit increases or decreases in the steady state without a change in the number of firms or the market. Conversely, the number of firms could change in the equilibrium without an effect on the profits. The latter case would correspond to a difference in the equilibrium levels of entry and exit. One could test various restrictions on $\kappa_{i}$. Another interesting hypothesis to test is whether "on average" $\log E_{i t}{ }^{*}=\log X_{i t}{ }^{*}$. This would imply that in the steady state the market does not grow or shrink. To formalize this hypothesis, we will mean center the variables in $W_{i t}$ such that the hypothesis can be stated as $\gamma_{1 i}=\gamma_{2 i}$.

The error terms are expected to be correlated within a market. In particular, we expect a positive correlation between entry and exit. We assume that there is no correlation over time or across markets. That is, we specify 


$$
\left(\begin{array}{c}
\varepsilon_{i t} \\
\eta_{i t} \\
\xi_{i t}
\end{array}\right) \sim N\left(0, \Omega_{i}\right)
$$

To economize on the number of parameters we restrict the covariance structure such that the correlations are the same across markets. We parameterize the variance such that

$$
\Omega_{i}=\left(\begin{array}{ccc}
\sigma_{\varepsilon_{i}} & 0 & 0 \\
0 & \sigma_{\eta_{i}} & 0 \\
0 & 0 & \sigma_{\xi_{i}}
\end{array}\right)\left(\begin{array}{ccc}
1 & \rho_{\varepsilon \eta} & \rho_{\varepsilon \xi} \\
\rho_{\varepsilon \eta} & 1 & \rho_{\eta \xi} \\
\rho_{\varepsilon \xi} & \rho_{\eta \xi} & 1
\end{array}\right)\left(\begin{array}{ccc}
\sigma_{\varepsilon_{i}} & 0 & 0 \\
0 & \sigma_{\eta_{i}} & 0 \\
0 & 0 & \sigma_{\xi_{i}}
\end{array}\right) \text {. }
$$

The $\rho$-parameters now denote the correlations between different error terms, while for example $\sigma_{\varepsilon_{i}}^{2}$ gives the variance of the error term associated with log entry for shop type $i$.

\section{Operationalization of variables}

We estimate our model for the earlier mentioned collection of shop types (industries) in the retail sector in the Netherlands, for the period 1980-2000. We use the following variables:

Key variables

$E_{i t} \quad$ number of entries in shop type $i$ during year $t$

$X_{i t} \quad$ number of exits in shop type $i$ during year $t$

$N_{i t} \quad$ number of firms in shop type $i$ at start of year $t$

$\pi_{i t} \quad$ total industry profit in shop type $i$ in year $t$ (in 1990 prices)

Variables included in vector $W$

modal income average modal income (in 1990 prices)

consumer spending total consumer spending in shop type (in 1990 prices)

unemployment number of unemployed (in millions)

Variables included in vector $Z$

Vector $Z$ contains the same variables as vector $W$. In addition, the real interest rate is included.

\section{Explanation of variables included in the model}

Equation (1) of our model describes the interrelations between entry, exit and total industry profits. Many studies of industrial organization model the interrelation between entry and exit (e.g. Carree and Thurik, 1996, Burke and van Stel, 2009). When a firm leaves the market, there is room for entry (replacement). When a firm enters the market, some other firm may be forced to leave the market because it is no longer competitive enough (displacement). Also, when profits in an industry are high, this attracts more firms (positive effect on entry) and incentives for firms to leave the market are low (negative effect on exit). Furthermore, when entry, exit or profits are above or below equilibrium, error-correction will cause these variables to move towards the steady-state level again. All these type of interactions between entry, exit and profits are captured by the coefficients contained in matrices $A$ (short-term effects) and $\Pi$ (adjustment effects) in (1).

Vector $Z$ in (1) contains exogenous explanatory variables for (changes in) entry, exit and profit levels. In our application the vector includes the variables modal income, consumer spending, unemployment and real interest rate. Modal income acts as an opportunity cost for running a 
retail shop, and hence this variable is expected to have a negative impact on entry and a positive impact on exit. Furthermore, an increase in modal income level may signal an overall upturn of the economy from which shopkeepers benefit as well (Carree and Thurik, 1994). Hence the expected impact on profits is positive. The growth rate of consumer expenditure on the goods and services sold in a shop type is an indicator for demand growth. This variable is expected to have a positive impact on entry, a negative impact on exit, and a positive impact on profits. Changes in unemployment may have a positive effect on entry as the (newly) unemployed may have limited alternative employment options in the wage sector (Thurik et al., 2008). Increasing unemployment rates are also a disincentive to exit as economic circumstances are not favorable to find a different occupation. Increasing unemployment will also put pressure on profit levels (expected effect on profits negative). High interest rates, finally, make running a business more expensive, hence the expected impact on entry is negative. Also, profit levels may be lower when interest rates are high.

With the exception of the real interest rate, the variables from vector $Z$ are also included in the vector $W$ capturing the long-term influences on entry, exit and profits. By and large, the arguments are the same as for the short-term impacts described above. The interest rate is not included in the long-run relationships for two reasons. First, the interest rate appears to be nonstationary. Therefore this variable cannot be related to the steady state levels of the stationary variables entry and exit. Second, the interest rate is expected to only affect the markets in the short run. That is, the interest rate mainly influences the moment to start a business (hence an impact in the short run) but not the decision as such to start a business. To the contrary modal incomes (indicator of opportunity costs), consumer spending (indicator of shop type-specific demand) and unemployment (indicator of general business conditions) may be seen as more structural, long-run, impacts on entry and exit. Note that the effects of unemployment in the long-run equations may be different from those in the short-term. In particular, the positive effect of unemployment on entry may be a short-term effect only, primarily relating to individuals who have just recently become unemployed, and want to start a business. In the long-term though, a structurally high level of unemployment indicates bad conditions for running businesses, implying a negative relation with entry.

As mentioned earlier, the profit equation also includes the number of firms. A higher number of firms or a higher level of total industry profits reflect a bigger market hence the expected relationship is positive. ${ }^{8}$ What is interesting is whether the parameter for the number of firms in the long-run profit equation (equation 2 in the model) is bigger or smaller than one. Note that we can rewrite the long-run relation for total profit as

$$
\log \left(\frac{\pi_{i t}^{*}}{N_{i t}}\right)=\gamma_{3 i}+W_{i t}^{\pi \prime} \delta_{3}+(\lambda-1) \log N_{i t}+\kappa_{i} t .
$$

The left hand side of this equilibrium relation gives the profit per firm. A $\lambda$ coefficient in excess of one suggests a positive relation between the equilibrium profit per firm and the number of firms. This implies that more firms leads to larger profits per firm. In other words, total industry profits increase disproportionally with an increase in number of firms. On the contrary, a coefficient smaller than one corresponds to decreasing average profits per firm.

\footnotetext{
${ }^{8}$ A coefficient of zero would imply that total industry profits remains the same (i.e. the market does not get bigger) when the number of firms increases, implying that the average profits per firm decrease proportionally with the increase in firms.
} 


\section{Estimation results}

We use the model as described in (1) to (4) to analyze 41 different shop types in the Dutch retail sector. Parameter estimation is done by numerically maximizing the log likelihood function using Ox 5.1 (Doornik, 2007). The likelihood function can straightforwardly be obtained from the model specification.

We present the estimation results in Table 4. First we comment on the long-run relationships. Modal income is negatively related to the long-run levels of entry and exit. This implies that if the modal income is high there are fewer firms entering the market and fewer firms leaving the market at any point in time. In other words, there is less turbulence. ${ }^{9}$ The impact of modal income on entry is the largest, this perfectly corresponds to our conjecture that modal income acts as opportunity costs. Modal income and consumer spending have a positive impact on the long-run total profit levels. In this case, both variables indicate good economic conditions. The consumer spending also significantly impacts the long run entry and exit levels. If consumer spending is high entry levels are high. However, many of these entrants replace other firms as the coefficient of consumer spending on exit is comparable in magnitude and sign. If unemployment is high, business conditions are bad. Hence few firms enter the market and few firms exit. Turbulence in this case will be low. The equilibrium profit levels turn out to be significantly related to the number of firms. More firms correspond to higher total profit levels in equilibrium. However, the increase in profit levels is not large enough, that is average profit per firm decreases as the number of firms increases. The parameter estimate is not significantly different from one though.

The estimates for the adjustment parameters presented in Table 4 give insight in the way an outof-equilibrium situation is corrected. If the entry level is too high relative to the equilibrium level this leads to a short-term decrease in entrants in the next period and a short-term increase in the number of exits. The impact on profit levels is negligible. Interestingly, if the exit level is too high, this only gets corrected by a lower exit level in the next period. The entry rates and profit levels are not directly affected. Finally, excessive profits are corrected through a change in profits itself and by a (temporarily) higher number of entrants, who are attracted by the high profit level.

The short-run effects of the (lagged) endogenous variables can be best shown using impulse response functions. Such functions give insight on how external shocks affect all variables. The short-run effects of the exogenous variables are easier to evaluate as they correspond to the direct impact of a particular change. The direct impact of an increase in modal income is that entry levels drop and profit levels increase. The magnitude of these effects is relatively large. An increase in consumer spending again leads to a direct change in entry and profits: both variables increase. An increase in unemployment directly leads to an increase in entry and a decrease in profit. Finally, the interest rate has a direct impact on entry: an increase in the interest rate corresponds to lower entry levels as expected.

Finally, we discuss the estimated correlation structure. We find a relatively large correlation $(0.42)$ between the error terms associated with entry and exit. This positive correlation implies that many shocks lead to a change in both variables, that is, they tend to affect turbulence. The correlation between the errors in entry or exit and profit are rather small.

\footnotetext{
${ }^{9}$ Turbulence is the sum of entry and exit.
} 
Table 4: Parameter estimates for model given in (1) - (4), standard errors in parentheses

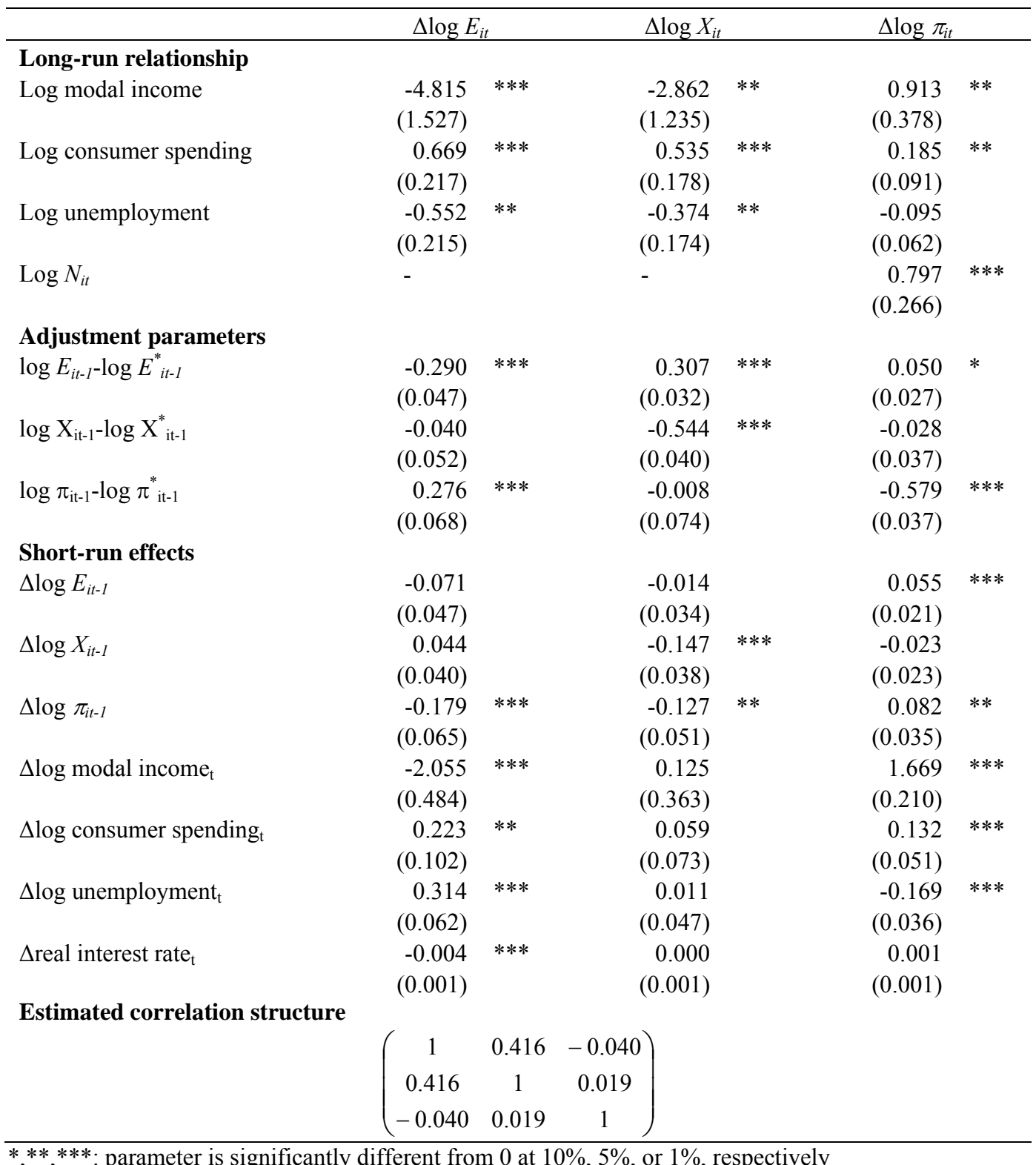

\section{Impulse response analysis}

In this section we use impulse response functions to study the impact of shocks to a market in equilibrium. We consider impulse response functions for four types of one-time shocks which give an insight into the economic development of the retail industry: a shock to profits, to the number of entrants, to the number of exits and to consumer spending. In each of these cases we investigate three dimensions of the adjustment process to equilibrium caused by the impact of these shocks: net change, time and pattern. Net change measures the total effect of the shock comparing the initial and the new equilibrium states. It is the Schumpeterian element of our investigation. Time is about the duration of disequilibrium between these states. It tests Schultz's assumption that disequilibrium is the norm rather than a rarity. Pattern is about the route that the adjustment process takes from the initial to the new equilibrium. Its analysis is important because most economic analyses are based upon comparative statics and monotonic 
adjustment processes. In all cases we consider a situation in which in the steady state there is no growth in the number of firms or total industry profits, that is, $\log E^{*}=\log X^{*}$ and $\kappa_{l}=0$. This situation enables an analysis of the effect of shocks. Furthermore, we assume that all exogenous variables are constant and equal to the observed mean value over time. Of course, in the case of the shock to consumer spending all other exogenous variables are assumed constant. In other words, we consider a one-time purely exogenous shock to a stable system. The size of the shock is taken as $1 \%$ of the steady state value prior to the shock. To initialize the simulation of the shock we need to set the initial number of firms. We select the first shop type available in the sample and use the first observed value of the number of firms as the initial value. The results do depend on this choice of initial value. This holds especially for the impact on the number of firms. The size of the shock on entry and exit is taken relative to its steady state. Depending on the turbulence in the shop type the resulting number of entrants or exits can be relatively small or relatively large.

Figure 1 shows the impact of a $1 \%$ shock to profits on five elements of the model including relative change in entry, exit, total profit, number of firms and profit per firm. Note that the various graphs have different scales on the y-axis. The graph shows that the impact on total industry profits reduces quickly over the course of the succeeding four to five years. Note however that the effect of the shock does not completely die out. In the end the profits are $0.04 \%$ higher. The effects on entry, exit and the number of firms are longer lasting. After the shock there is more entry and fewer exits. In later periods the entry rate stays above the original steady state level and the peak in the effect is obtained in year 4. For exit we find that the initial drop in the number of exits is followed by a rise. Probably some of the additional entrants either displace incumbent firms or exit the market relatively quickly. The model implies that the entry and exit levels return to their original steady state levels. The total number of firms increases permanently with about $0.05 \%$ as a result of the shock. In the long run the shock has almost no impact on the average profit per firm. It turns out to be slightly smaller than before the shock. Note that this is consistent with the parameter for $\log N$ being smaller than one in the long-run profit equation.

In terms of the three dimensions of the adjustment process to equilibrium, we observe that the positive shock to profits is informative. First, we note that while there are no long term changes to entry and exit, the short term rise in profits causes a permanent increase in the number of firms. This is associated with lower average profits per firm but higher total industry profits. Therefore, in terms of net change the shock to profits has a permanent effect on the economic size of the retail industry. Second, the timing of this adjustment process lasts approximately five years between the initial and the new equilibrium for profits but 15 years for entry, exit and the total number of firms. Thirdly, the pattern of the adjustment process is in part fairly straightforward - after the profit shock net entry rises and the rise in the total number of firms causes profits to converge monotonically to the new equilibrium. However, the exit rate oscillates, initially 'undershooting' and then 'overshooting' the long run equilibrium.

Hence, as a result of the positive shock to profits, the number of firms permanently increases and the average profit per firm permanently decreases. However, the latter effect is smaller than the former effect, implying a permanent increase in total industry profits. If we interpret the shock in profits as some kind of product differentiation or innovation by some incumbents (the industry induces a higher willingness to pay by offering new and more valuable products or services), we see that this has a small but lasting positive effect on the size of the market, both in terms of the number of firms and in terms of total industry profits. The turbulence (high entry and exit rates) in the first decade after the shock are a clear sign of the learning process of the 
industry: entry through use of new technology and exits as a result of being unable to keep up with the new technology.

\section{Figure 1: Effect of a 1\% shock to total industry profits, all graphs give the change relative to the steady state levels prior to the shock.}
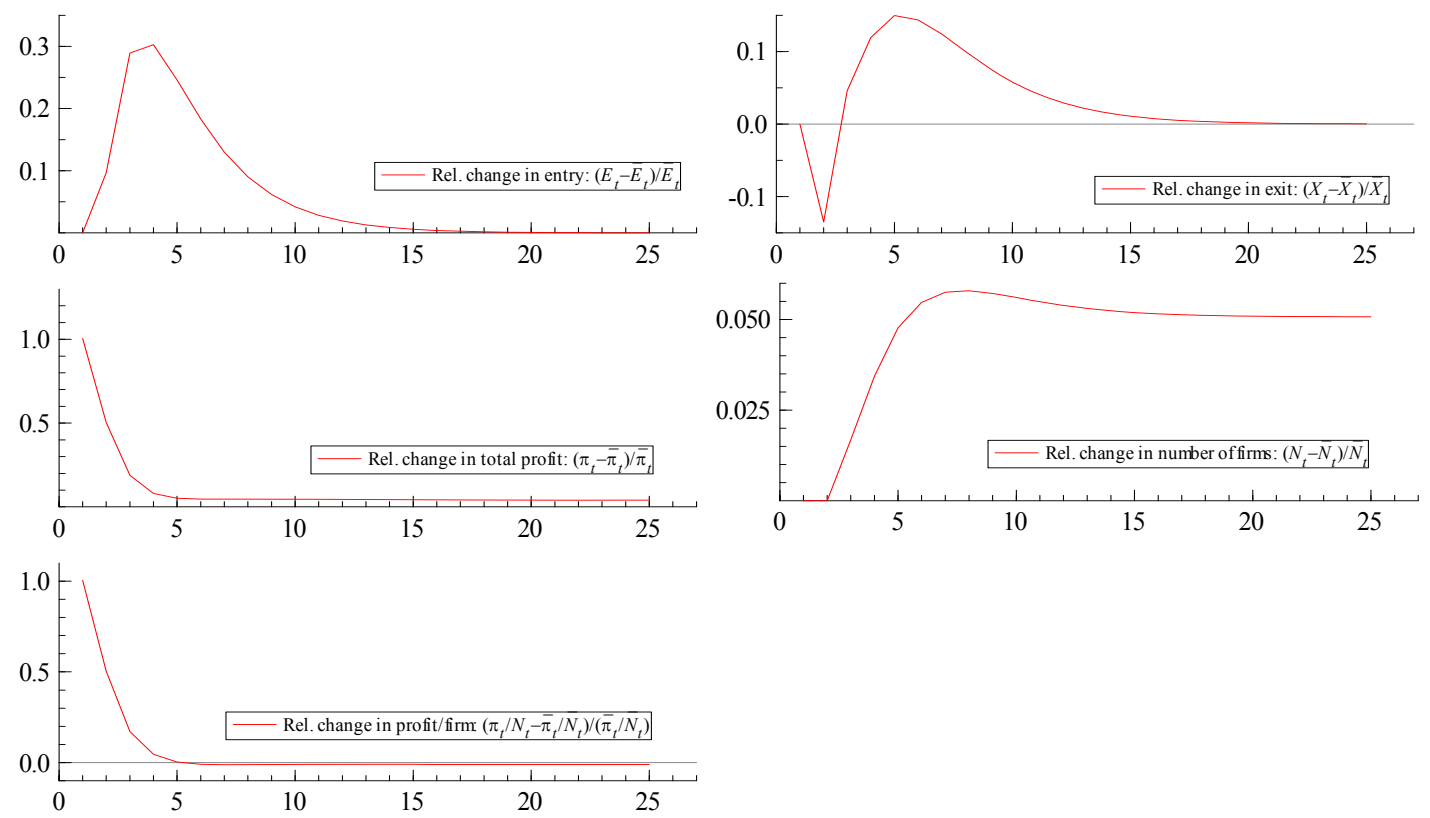

Figure 2 shows the result of a 1\% shock to entry on the five elements of the model including relative change in entry, exit, total profit, number of firms and profit per firm. The result of this shock is to cause more exit for at least 15 years, and permanently higher levels of total profits and the number of firms. However, since the increase in the number of firms is slightly larger than the increase in total profits, the average profit per firm decreases by about $0.02 \%$.

Hence, similar to the shock to profits (Figure 1), as a result of the positive shock to entry, total profits as well as the number of firms permanently increase and the average profit per firm permanently decreases. In terms of the three dimensions of the adjustment process to equilibrium, we again observe the shock to entry is insightful. First we note that while there are no long term changes to entry and exit, the short term rise in net entry causes a permanent increase in the number of firms. This is associated with lower average profits per firm but higher total industry profits. Therefore, in terms of net change the shock to entry has a permanent effect on the economic size and competitiveness of the retail industry. Second, the timing of this adjustment process is far from instantaneous lasting approximately ten years between the initial and the new equilibrium. Thirdly, the pattern of the adjustment process is non monotonic but oscillates before it settles on a convergent path towards the new equilibrium. This is particularly noticeable with profits per firm which first 'overshoots' and then 'undershoots' before finally converging towards the new equilibrium.

If we interpret the shock to entry as driven by an entrepreneurial desire to introduce innovation we see that it causes a permanent increase in the size of an industry and total industry profits. In the process it causes a turbulent environment for firms with long periods of disequilibrium and with profits per firm fluctuating before finally converging on lower average profit levels per 
firm. The question now is why this shock leads to reduced firm level profits and more firms. The story could be as follows: first, while firm-level sales are reduced, prices may increase. The reason is that the entrant now offers a more customized product to some of the consumers incumbent firms were selling to. These were the most price-sensitive consumers previously (they switch because they were not satisfied with existing products, hence had the lowest willingness to pay). With the most price-sensitive customers gone, incumbent firms raise their prices because there is no point going after those who now have a product available that they like much better. This all explains why industry sales and prices, hence industry profits, may increase after entry. It is also consistent with reduced firm-level profits: incumbent firms have lower sales. Second, after the differentiated entry, the incumbents have an incentive to also differentiate their products from each other, in order to limit price competition. As a result, the market becomes more segmented. This may open up more niches for additional entrants and, as is shown in Figure 2, there may be an exit wave after some time where entrepreneurs realize that the niche they targeted was not profitable enough. Hence the 'entry causes more entry' relationship.

\section{Figure 2: Effect of a 1\% shock to entry, all graphs give the change relative to the steady state levels prior to the shock.}
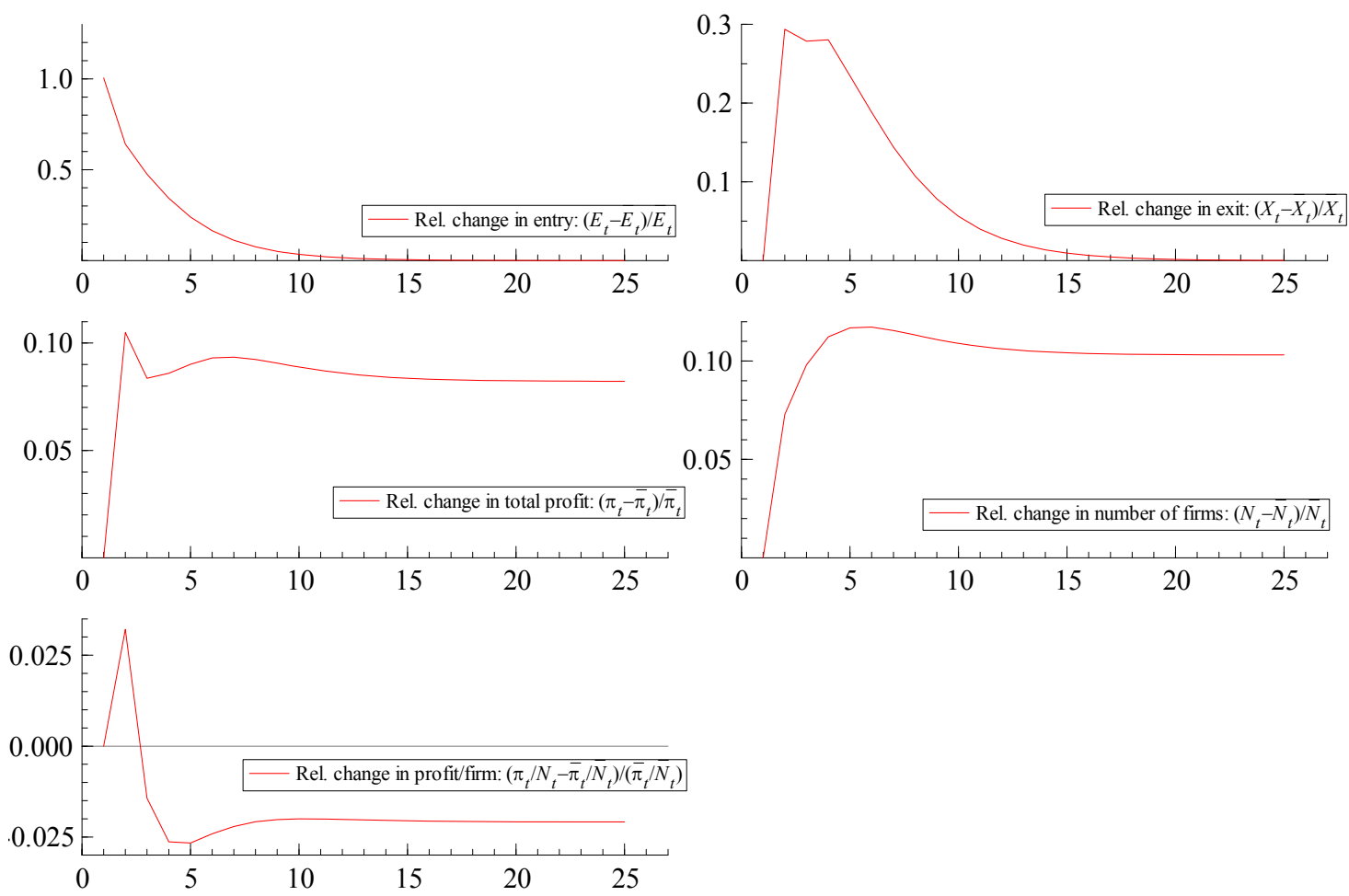

An exogenous shock to the number of exits has a somewhat different impact. Figure 3 shows that, although initially this shock results in more entrants, overall the shock leads to less entrants during a relatively long period of time. However, the size of this impact is relatively small (note the different scales on the y-axes for entry and exit). In the new steady state profit levels have decreases by more than $0.10 \%$, the number of firms has decreased by about $0.14 \%$. In terms of average profit per firm, this shock leads to an increase of approximately $0.03 \%$. 
In terms of the three dimensions of the adjustment process to equilibrium, we observe the following. First we note that there is no permanent change to the equilibrium rate of entry and exit. However, there is a net decrease in the equilibrium number of firms and industry profit meaning that the industry does not fully recover its initial equilibrium. The equilibrium average profit per firm rises; associated with the fall in the total number of firms. Second, the timing of the adjustment process to the new equilibrium is slow taking between ten to fifteen years. Thirdly, the pattern of the adjustment process is not monotonic. Initially the shock to exit has a sustained affect causing the exit rate to stay above equilibrium for 6 years, over and beyond which the entry rate also falls below the long run equilibrium, so that both then contribute to the net fall in the total number of firms. Hence, in the case of a positive shock to exit the striking result is that the market never fully recovers: the size of the market decreases, both in terms of the number of firms, and in terms of total industry profit. ${ }^{10}$

\section{Figure 3: Effect of a 1\% shock to exit, all graphs give the change relative to the steady state levels prior to the shock.}
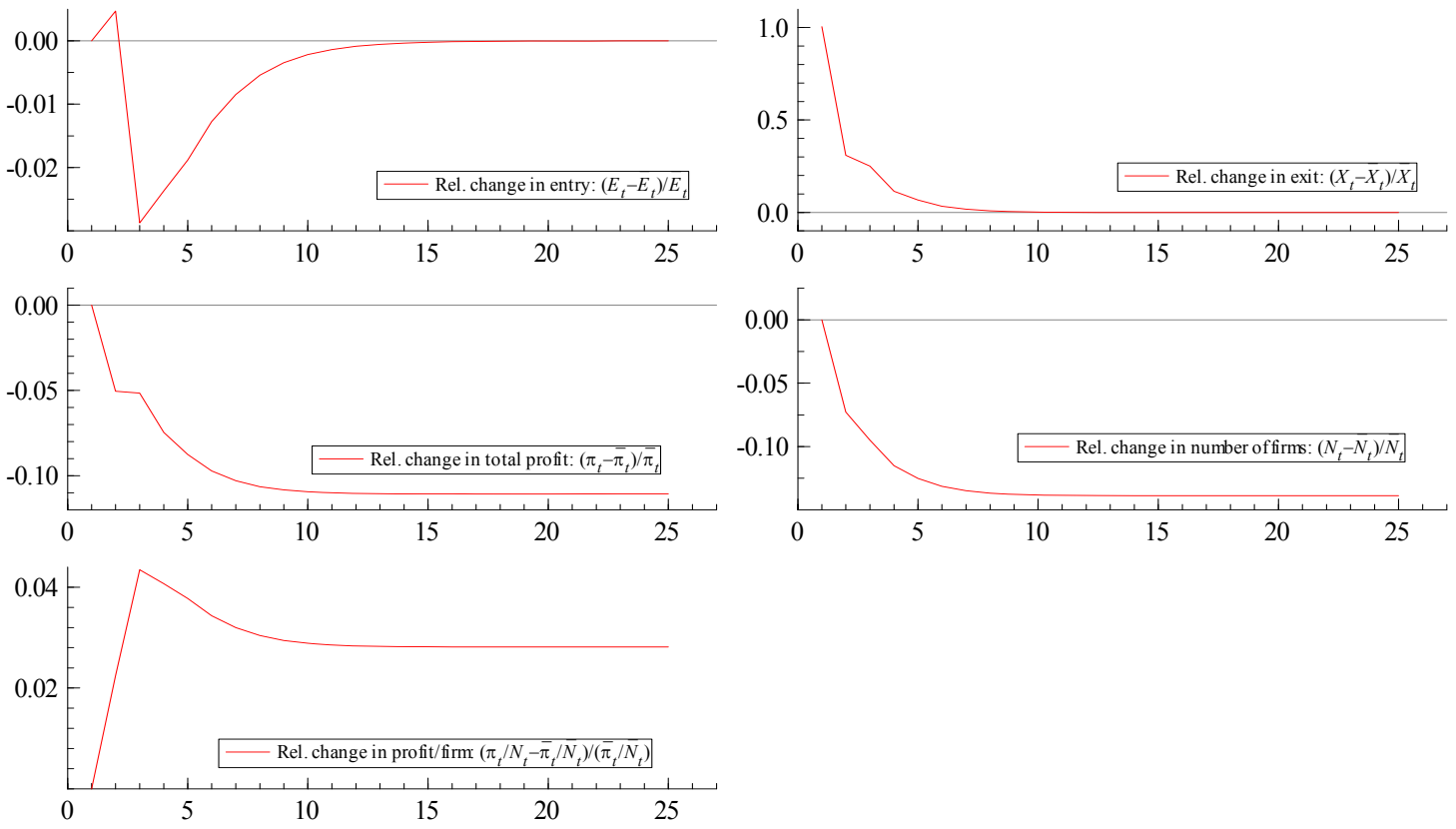

Figure 4 shows that a shock in consumer spending leads to more entry and exit for at least 15 years while leading to a higher number of firms and total profits. Since the increase in the number of firms is slightly higher than the increase in total profits, average profits per firm decreases.

In terms of the three dimensions of the adjustment process to equilibrium, we first note that there are no long term changes to entry and exit. However, the shock in consumer spending leads to permanent increase in the number of firms. This is associated with lower average

\footnotetext{
${ }^{10}$ An interpretation is that a demand shock is at the origin of industry events. Marginal firms cannot keep up with a change in consumer preferences and leave the market. The adapting incumbents together with differentiated entrants are able to convince consumers to lower their price sensitivity given their new taste. As can be seen in Figure 3, entry is frustrated with a delay after the change in consumer preferences because of uncertainty signalled by the wave of exits. The resulting higher prices lead to higher industry profits in an altogether smaller market. Those firms which 'survive' the shock to exit are slightly better off, as average profits increase.
} 
profits per firm but higher industry profits. The shock in consumer spending appears to have a permanent effect on economic size and competitiveness of the industry. Second, the timing is again far from instantaneous: it seems that the number of firms and industry profits are close to their new equilibrium while in the subsequent decade there is still some turbulence (entry and exit). Third, the pattern of the adjustment process is not monotonic but there is an upsurge in all variables before a monotonic path to equilibrium is reached. The adjustment process of this shock to consumer spending is similar to that of entry with the exception that the early oscillations are weaker (of course, a one percent shock in consumer spending cannot be compared to a one percent shock in total entry). ${ }^{11}$

Figure 4: Effect of a 1\% shock to consumer spending, all graphs give the change relative to the steady state levels prior to the shock.
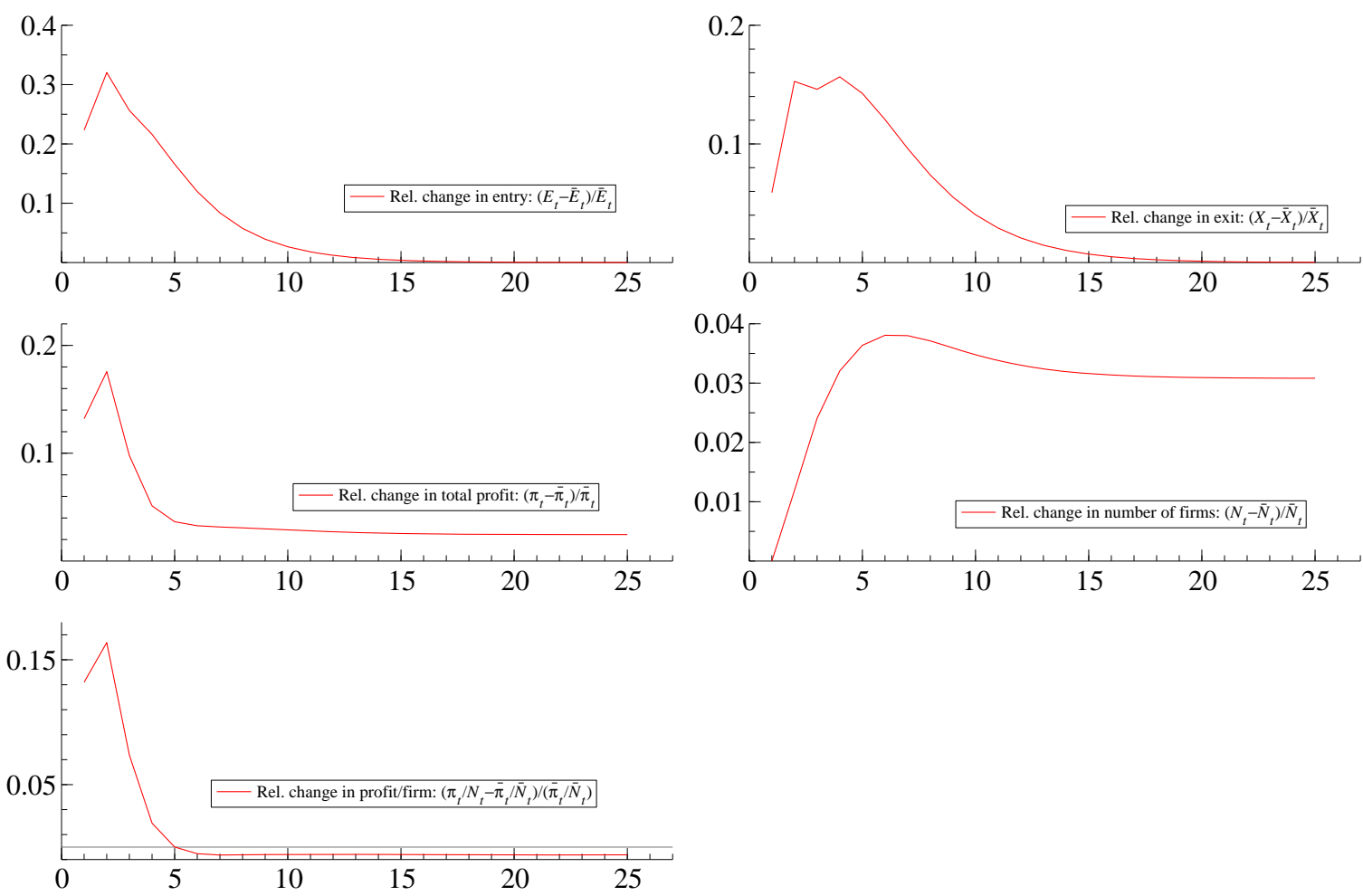

In general, the four shocks described above lead to permanent change in the industry, i.e., a new equilibrium. In this process entrants are found to play two roles. Initially, they perform an entrepreneurial function of creating disequilibrium; permanently undermining the existing equilibrium. Thereafter they play the conventional equilibrating role of moving the industry to a new equilibrium. For instance, a shock to exit has a permanent effect in that the market does not recover as opposed to one in profits which has a permanent positive effect on the size of the market. These shocks cause a long period of disequilibrium, typically 10 to 15 years, indicating the importance of the entrepreneurial function of entry and exit. This provides support for the

\footnotetext{
${ }^{11}$ An interpretation of this direct (consumer spending) demand shock is not necessarily similar to that of the indirect (entry) demand shock. An upward shift in consumer spending provokes entry of firms using a better technology. This new competition leads to lower profits per firm while total industry profits as well as the number of firms grow due to increased consumer spending.
} 
Schultzian view that disequilibrium is the norm rather than the oddity. Moreover, we observe not only long periods of disequilibrium but also many non-monotonic adjustment processes which highlights their complexity. Frequently these processes are initially 'erratic' before earnest convergence to the new equilibrium sets in.

Surprisingly, we observe that in all four cases industry profits and number of firms move in the same direction: upwards in the case of a shock to profits, entrants and consumer spending and downwards in the case of a shock to exits. Let us take the case of the entry shock. There are two possible reasons why entry may be associated with higher long-term industry profits. One is an exogenous and lasting increase in demand; the other is that the industry induces a higher willingness to pay by offering more valuable products (i.e., there is some kind of innovation). Distinguishing between these two causes of the entry shock is not possible given our present results. In the demand-driven case, there is no reason why entrants, rather than incumbents, should respond to the shock. For instance, it makes more sense for there to be an adjustment phase with entry and exit rates deviating from their normal levels if entry is innovative (differentiated) and thus has less certain consequences. In the case of the direct shock in consumer spending entrants with a new technology bring about competition together with a turbulent phase involving both entry and exit while ultimately industry profits and number of firms increase.

\section{Conclusions}

The development of industries and economies is driven to a large extent by the process of entry and exit of firms. It is an important determinant of market performance in terms of productivity and structure. Much is known about the interplay between entry and exit (Carree and Thurik 1996), their variability over time and industries (Geroski 1995) and the way they bring about change (Audretsch 1995; Baumol 2002; Bartelsman et al. 2004). The relation between profits and the number of firms in a market is another essential topic in the field of industrial organization. Usually, the relation is modeled in an error-correction framework where profits and/or the number of firms respond to out-of-equilibrium situations. In an out-of-equilibrium situation one or both of these variables deviate from some long-term sustainable level. These models predict that in situations of equilibrium, the number of firms does not change and hence, entry equals exit. Moreover, in equilibrium entry and exit are expected to be equal to zero. These predictions are at odds with real life observations showing that entry and exit levels are significantly positive in all markets of substantial size. Moreover, entry and exit levels often differ drastically. In this paper we develop a new model for the relation between profit levels and the number of firms by specifying not only an equation for the equilibrium level of profits in a market but also equations for the equilibrium levels of entry and exit. In our empirical application we show that our entry and exit equations satisfy usual error-correction conditions. We also find that a one-time positive shock to entry, profits or consumer spending has a small but permanent positive effect on both the number of firms and total industry profits. This can only be explained by the introduction of innovation and/or product differentiation.

The results indicate that both the classical and entrepreneurial models of the interrelationship between entry, exit and profits have some empirical foundation. Contrary to the premise for the stand off between classical economists and Schumpeterian and Austrian economists, the results show that these models coexist. They both explain different parts of industry dynamics. Moreover, we created room for the Schultzian view that disequilibria are inevitable features of economic progress and measured the duration and patterns of these disequilibria. We provide evidence of the length and the complexity of the adjustment processes. This supports Schultz, Baumol and the Austrians when they argue that the main challenge of economics is to explain disequilibrium processes. The results indicate that entry has a short term classical competitive 
positive effect on exit as well as a Schumpeterian disequilibriating one. But we also find a long term positive Austrian effect of entry on both the number of firms and total industry profits. This evidence is consistent with a view where entrants are entrepreneurial and have creative destruction competitive effects on average profits of firms. Interestingly, the results run counter to a view which associates innovation with the generation of monopolistic power as our results for Dutch retailing indicate exactly the opposite. In fact, entrepreneurial entrants seem to play a dual beneficial role in terms of being both pro competitive and innovative.

\section{References}

Audretsch D. 1995. Innovation and Industry Evolution. MIT Press, Cambridge, MA.

Barreto H. 1989. The Entrepreneur in Microeconomic Theory: Disappearance and Explanation. Routledge, London.

Bartelsman E, Haltiwanger J, Scarpetta S. 2004. Macroeconomic Evidence of Creative Destruction in Industrial and Developing Countries. IZA discussion paper series No. 1374, Bonn.

Baumol, WJ. 2002. The Free-Market Innovation Machine: Analyzing the Growth Miracle of Capitalism. Princeton University Press, Princeton, NJ.

Breitung J. 2000. The Local Power of Some Unit Root Tests for Panel Data. In Advances in Econometrics: Nonstationary Panels, Panel Cointegration, and Dynamic Panels, Baltagi B. (ed.), vol. 15, JAI Press: 161-177.

Burke AE, van Stel AJ. 2009. The Entrepreneurial Adjustment Process in Disequilibrium. Tinbergen Institute Discussion Paper TI 2009-005/3. Amsterdam-Rotterdam: Tinbergen Institute.

Carree MA, Thurik AR. 1994. The Dynamics of Entry, Exit and Profitability: An Error Correction Approach for the Retail Industry, Small Business Economics 6: 107-116.

Carree MA, Thurik AR. 1996. Entry and Exit in Retailing: Incentives, Barriers, Displacement and Replacement, Review of Industrial Organization 11: 155-172.

Choi I. 2001. Unit Root Tests for Panel Data. Journal of International Money and Finance 20: 249-272.

Doornik JA. 2007. Object-Oriented Matrix Programming Using Ox, 3rd ed. London: Timberlake Consultants Press and Oxford: www.doornik.com.

EIM (2009). Internationale Benchmark Ondernemerschap 2009 (in Dutch). EIM Report A200913, Zoetermeer, NL: EIM.

Engle RF, Granger CWJ. 1987. Co-integration and Error Correction: Representation, Estimation, and Testing. Econometrica 55: 251-276.

Geroski PA. 1995. What Do We Know about Entry? International Journal of Industrial Organization 13:421-440.

Im K, Pesaran MH, Shin Y. 2003. Testing for Unit Roots in Heterogeneous Panels. Journal of Econometrics 115: 53-74.

Kirzner IM. 1973. Competition and Entrepreneurship. University of Chicago Press, Chicago.

Levin A, Lin C, Chu C. 2002. Unit Root Tests in Panel Data: Asymptotic and Finite-Sample Properties. Journal of Econometrics 108: 1-24.

Maddala G, Wu S. 1999. A Comparative Study of Unit Root Tests with Panel Data and a New Simple Test. Oxford Bulletin of Economics and Statistics 61: 631-652.

Nooteboom B. 2000. Learning and Innovation in Organizations and Economies. Oxford University Press, Oxford.

Pedroni P. 1999. Critical Values for Cointegration Tests in Heterogeneous Panels with Multiple Regressors. Oxford Bulletin of Economics and Statistics 61: 653-670.

Pedroni P. 2004. Panel Cointegration; Asymptotic and Finite Sample Properties of Pooled Time Series Tests with an Application to the PPP Hypothesis. Econometric Theory 20: 597-625.

Schultz TW. (1975),. The Value of the Ability to Deal with Disequilibria. Journal of Economic Literature 13 (6): 827-846.

Schumpeter, JA. (1947). Theoretical Problems of Economic Growth. Journal of Economic History 7: 1-9.

Thurik AR, Carree MA, van Stel AJ, Audretsch DB. 2008. Does Self-employment Reduce Unemployment? Journal of Business Venturing 23 (6): 673-686.

Wennekers S, Thurik AR. 1999. Linking Entrepreneurship to Economic Growth. Small Business Economics 13 (1): 27-55. 